\title{
Emotional Intelligence and Ethics on Organizations
}

\author{
Ângelo Miguel Rodrigues Cabral, Fernando Manuel Pereira de Oliveira Carvalho \\ Faculty of Economics, University of Coimbra, Coimbra, Portugal

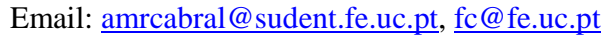

Received November 13, 2013; revised December 15, 2013; accepted January 10, 2014

Copyright (C) 2014 Ângelo Miguel Rodrigues Cabral, Fernando Manuel Pereira de Oliveira Carvalho. This is an open access article distributed under the Creative Commons Attribution License, which permits unrestricted use, distribution, and reproduction in any medium, provided the original work is properly cited. In accordance of the Creative Commons Attribution License all Copyrights (C) 2014 are reserved for SCIRP and the owner of the intellectual property Ângelo Miguel Rodrigues Cabral, Fernando Manuel Pereira de Oliveira Carvalho. All Copyright (C) 2014 are guarded by law and by SCIRP as a guardian.

\begin{abstract}
Purpose: The purpose of this study was to explore the role of Emotional Intelligence on Individual Ethics, Perceptions of Other's Ethics and Ethics Perception in Facilitating Success. Methodology: Constitute the sample 404 exporting companies and/or with interest in exporting of AICEP database-Portugal Agency for Investment and External Commerce. The methodological procedures adopted in the research, consisted of a quantitative approach using fundamentally multiple regression analysis and hierarchical regression too. Data collection was performed by administering a questionnaire. Findings: Emotional Intelligence predicted perceptions of the role of Ethics in Success. The role of Emotional Intelligence was attested as a predictor in Individual Ethics, and the predictor role of these two in Perceptions of Other's Ethics. Emotional Intelligence was significantly correlated with Self-Esteem, Social Desirability, Individual Ethics and Perceptions of Other's Ethics.
\end{abstract}

\section{KEYWORDS}

Emotional Intelligence; Emotion; Ethics; Organizations

\section{Introduction}

Emotional Intelligence, Ethics, Ethics Perceptions and Success were established as theme of this research because of its relevance and its contextualization on management horizon. The curiosity, analysis and research about the emotional spectrum of the human species transport us to ancient times [1]. Reference [2] alludes to the fact that the inter-relational capabilities in organizations, the ability to change others as a leadership technique with the inherent recurrence to the use of emotions - their empathic value of understanding, changing and development of other's-are the worst-kept secret in the world, since ancestral figures as Christ, Buddha, Mohammed, Confucius and Aristotle already reported it for thousands of years. The need to assess the role of emotion and Emotional Intelligence (EI) on a global scale is a revealing trace of recent times, and not devaluating that in favour of other concepts, such as the Intelligence Quotient (IQ), as, and according to Reference [1] our performance in life is determined not only by IQ, but mainly by the Emotional Quotient (EQ). In this sense as a clear route of change, according to Reference [3] "evidences

have been accumulated in recent years showing that the act of feeling, thinking and deciding involves a joint effort of the emotional and rational brain. With this, neurologists have ended the old secular dualism between body and soul, on the one hand, and between reason and emotion, on the other" (p. 15). Thus, "when these partners interact well, emotional intelligence increases, as well as his intellectual capacity. This brings down the myth that we should override reason to emotion and stirs the search for balance between them” [4] (p. 150), as also reiterates Reference [5]. According to Reference [1] "We went too far in the emphasis that we place the value and importance of the purely rational-what IQ measuresin human life. For better or for worse, intelligence may not have the minimum value when the emotions speak" (p. 26). In a corollary tone of coverage, Reference [1] states that "a view of human nature that ignores the power of emotions is sadly shortsighted” (p. 26). As one of the main resources, being the Human organizationally stands the impacting power of emotion and Emotional Intelligence. The current prominence of the study of emotions in relationship with organizational management 
e.g. [6], suggests that the emotional factor coupled with ethics will have decisive implications in present competitiveness in the exporting and/or interested in exporting companies, given the cultural differences, behavioral, emotional and ethical issues faced. Emotions appear to be intrinsic to a rational process of ethical decision, so there's the necessity to not ignore them nor take them as distortion factor of rationality, but, to index them in this process, which certainly will lead to better ethical behaviors [6].

The potential merit underlying the evaluation, use and regulation of emotion in EI [7], is fundamental in consciousness, attitude and ethical behavior because, "there are growing evidences that we make fundamental ethical positions in life stem from underlying emotional capacities” [1] (p. 20). Therefore, EI and Ethics are determinant on rationalized and emotional integration of human behavior, and inherently in society and in organizational world. Ethics and EI are important too in the attenuation of dramatic and unbalanced wills that tend to persist. A greater awareness of ethical misconduct prevalence of individuals and in organizations is required, and has generated increased great interest among scholars [8-12]. Is it pertinent to study human values in a business context? According to Reference [13] "one unexplored variable with the potential to impact ethical behavior and decision-making is emotional intelligence” (p. 35). The authors mentioned further that "to date, no empirical research has examined the EI-ethical perceptions link” (p. 36), what initiates as innovative from a scientific point of view and driving new ideas and management philosophies. This study followed the line of investigation of these authors. Three main research questions are driven this study: 1) does EI predict the occurrence of unethical and/or counterproductive behaviour? 2) does EI predict perceptions of others ethicality? and 3) does EI predict perceptions that unethical behavior facilitates success?

\section{Literature Review}

\subsection{Emotional Intelligence}

For organizations, is important that they be aware of an issue now seen as a critical success factor-Emotional Intelligence. With the purpose to understand Emotional Intelligence is essential to analyse and investigate the concepts of intelligence and emotion, given its cooperative combination context [5,14,15].

Commonly, intelligence refers to the characterization of how well the cognitive sphere works, in particular the conceptual skills of, judging, reasoning and process abstract thought [5]. Many authors have defined and define intelligence sometimes with different strands and nuances, but in general is seen as a broad range of mental abilities [16,17]. Reference [14] allude to this difficulty, and even to the fact of not being possible to know all its facets and to say there is nothing more to be found. Intelligence is defined as the ability of valid reasoning about a branch of knowledge, typically requires a single answer or solution, and is commonly associated with the achieved academic skills and with the prestige of the functions that each one performs [17]. Reference [18] states that "intelligence comprises the mental abilities necessary for adaptation to, as well as shaping and selection of, any environmental context” (p. 1030), and one of the inputs with high intellectual repercussions are emotions [19]. Many authors e.g., [1,16] argue that standard measuring models of intelligence sin for the lacunae they have, given the complexity of human being, which according to Reference [20] can hardly be manifested only in the resolution of academic or work problems, with the need to devote the social, self-knowledge and the emotional scope. To evaluate the Emotional Intelligence, there are two competing models for its conceptualization, the model of mental abilities originally defined by Reference [5] which is based on performance models, and results from an interaction of emotion and cognition reflecting processing capacity and reasoning with emotions Reference [21], and the mix models that allow the presence of other constructs such as personality in combination with emotional skills, of wich the model of Reference [1] is an example [22-24].

Over the last few years there has been a reassessment of the power of emotion legitimizing it next to the intellectual rigor [14]. Emotion is a sine qua non condition of Emotional Intelligence construct, is one of the conceptual vertices along with intelligence. However, often these two vertices were seen as opponents with the emotions an intrinsically irractional role [14]. Presently they are seen as a potential contribute to thought, instead of desorganize it [5]. Defining emotion, in the words of Reference [25] "has proved to be as difficult to resolve as the emotions have been to master" (p. 3). Is required a brief explanation between emotion and feeling. Reference [26] states that "emotion and feeling are distinguishable processes, although being part of a too tight cycle” (p. 142). Reference [25] calls attention to the conceptual complexity of emotion and feeling, putting as a point of order, the fact that emotions hold a cognitive component and not just feelings or physiological processes, referring that a feeling is not enough to produce an emotion, existing emotionally a conjunction of cognition and feeling. Feelings are "perceptions of what happens in the body and mind when we feel emotions", are according to Reference [26] "the composed perception of everything that happened during the emotion slow or fast, fixed in an image, or rapidly changing an image with another one” (pp. 143-144). Reference [16] views emotions as "organized responses, crossing the boundaries of 
many psychological subsystems, including physiological, cognitive, motivational and experimental systems” (p. 186), emerging as responses to internal or external events with positive or negative personal meanings [27], being distinct from the state of mind, given the shorter and more intense nature of the emotion.

The concept of Emotional Intelligence arises proposed by John D. Mayer and Peter Salovey in 1990 [28], through an article in the magazine "Imagination, Cognition and Personality" [29], and not by Daniel Goleman as often judged. It is observable a stimulating body of research in EI, but with a still lack of onceptual consensus which led to a different measuring instruments proliferation [30]. This body of research is still dismembered and dispersed [16]. The domain of reasoning that takes into consideration the emotions, namely, the use of emotions as a basis for thought and hink with them is part of what is considered Emotional Intelligence by Reference [5]. According to Reference [5] EI is "the ability to perceive accurately, appraise, and express emotion; the ability to access and/or generate feelings when they facilitate thought; the ability to understand emotion and emotional knowledge; and the ability to regulate emotions to promote emotional and intellectual growth" (p. 10). There is an explicit "marriage" between emotion and cognition in this definition [31], therefore, the autors defined EI as the ability to recognize the meaning of emotions and their relationships, the reasoning and problem solving based on emotional knowledge [27]. In its turn, Reference [1], defines EI as "a person's ability to motivate herself and persist despite the frustrations; to control impulses and delay reward; to regulate their own mood and prevent discouragement overwhelm the faculty of thinking; to empathize and feel hope” (p. 54). Reference [14] consbstantiates EI to the "competence to identify and express emotions, understand emotions, assimilate emotions in thought, and regulate both positive and negative emotions in the self and in others" (p. 3).

Reference [5] divides the construct of Emotional Intelligence into four branches of abilities, that they have designated as "the four branch model" where the $1^{\circ}$ "Perception, Appraisal, and Expression of Emotion" consists in the capacity or ability of conscious and accurate identification of the emotions and the emotional content and the accuracy of emotional expression as well as the feelings related expression, the $2^{\circ}$ "Emotional Facilitation of Thinking" refers to the emotions ability of prioritizing thought directing it to important information, the $3^{\circ}$ "Understanding and Analysing Emotions; Employing Emotional Knowledge" consigns comprehension skills of complex feelings and emotional transitions such as love-hate, and interpretation of the emotions meaning, and finally the $4^{\circ}$ branch "Reflective Regulation of Emotions to Promote Emotional and Intellectual Growth" refers to the ability of conscious emotions regulation to promote emotional and intelectual growth. Emotional Intelligence represents an intelligent system of processing emotional information and shows itself as being transverse to cognitive and emotional system, where could be verified that giving Reference [14] "the interest generated by the EI construct is part of the current zeitgeist of modern Western society, which is increasingly recognizing the importance of emotions" (p. 8).

Reference [1] refers that adults with high levels of IQ may prove to be socially inept, and according to Reference [32], the evaluation power of IQ tests must be questioned, taking into account the idiots savants profile, attempting actions for bigger and better emotions assumption, allying them to reason. It seems fair to affirm that there is a social, cultural and economic instrumentalization of abstract reasoning, which should be balanced not according to the socially stereotyped guidelines, but with deep knowledge in technique, clinic and ethics. Going to meet these expectations, seems to emerge a particular sensitization for an "emotional rebellion" of rational desacralization as the sine qua non condition of the existential essence of human being. Therefore not circumscribing the power of intellect to cognition, but consecrating resolutely emotional competencies inherent in the human being, it is visible as above, an eminet and increasingly recognized power of emotion by the scientific community in the individuals life environment. it is clear an increasing emphasis on emotional management of the human being in modern society [14].

It is opened, therefore, an opportunity window and a necessity window, for the Emotional Intelligence exponential growth as a discipline, since the traditional cognitive predictors let a substantial margin in the organizational and educational context performance to explain [22]. The theory predicts that EI is a valid inteligence as the others $[15,27,33]$ and the authors of Reference [19] state that is a traditional intelligence which represents the core competence domain to reason with emotions [5, $15,27]$, because obeys to the three required empirical criteria for classification as intelligence, the conceptual, the correlational and the development based [27]. Emotional Intelligence as recent generation concept, has a wide range of contributions, some more consensual than others, where must be highlighted as common feature to all jobs, the general acceptance that EI improves qualitatively the human being [31]. It should be emphasized that the development and understanding of an intelligence requires a considerable number of years of careful scrutiny and investigation. Reference [5] refer that "presently, we are at the beginning of the learning curve about emotional intelligence" (p. 22), being its measurement in childhood stage [22]. It is noteworthy that one of the most widely used intelligence scales, Wechsler Intelli- 
gence Scale, is the product of 60 years of research, with the research itself initiated after the first 40 years of clinical evaluation work in intelligence [15].

The predictive value of Emotional Intelligence is important for several areas, such as life satisfaction $[34,35]$, research and clinical application [36], school environment and academic success [14,15] and organizational context, where EI is able to predict the good performance and work success [22-34], as well as contribute to a better working environment [37]. In organizational reality is patent the magnanimity of emotion by the people that integrate it. Another key issue and remarkable figure as organizational system vertex is Ethics and their respective ethical or unethical conduct, where emotions may have a leading role and contribute to the strengthening and integration of ethical appeals more and more verified and with very future benefits. The field of emotions is form an early age referenced from the ethical point of view [25]. It is important to realize the connection of emotional management, the reasoning supported by emotions, namely, of EI in its fullness with the ethical attitude and behavior, because urges the need to annihilate much of the "anything goes"-systematic confrontations with recourse to mistake, the lack of transparency, defensive communication, authoritarianism and mediocrity of the great majority [38] — politics that passes and cuts across by individual behaviors on the organizational scope and on life in general. Ethics and emotion, historical and contemporaneously have been and are interconnected [25].

\subsection{Ethics}

Ethical concerns have been the subject of unprecedented attention by management and business literatures, where ethics represents a set of values that seeks to define what is "good", and a set of principles that guide human behavior in order to achieve this, where the sense of social justice is latent [39]. Reference [40], adopted by this study, states that ethics is "the study and philosophy of human conduct with an emphasis on the determination of right and wrong” (p. 207). Reference [41] refers that "speaking about ethics is, thus, speaking about the reflective determination of the good human action conditions, the place where rests the purpose of the act” (p. 129). Reference [38] says that "We must never forget that Ethics has to do with true values, which every woman and every man should feel obliged to incorporate into their own life and that every company has an obligation to promote I their internal and external context” (p. 14). The concept of ethics by Nicholas Hobbs in "International Encyclopaedia of Social Sciences" says that "ethics refers to conduct standards among people in social groups" [42] (p. 160). It is worthwhile to refer the ethical vision of Reference [38], which says that "ethics is a science, neither a belief nor the product of political consensus, is a knowledge that can be learned with the help of reason and experience" (p. 95).

Individual ethical behavior of all that incorporate an organization should be a virtue in constant development, being furthermore a competitive "agent", because markets in the day today demand ethics from the entrepreneur and from companies [43]. Should be noted that in an ethical behavior there is no mandatory nature of profitability, because if it were the case, it could be inferred, a little or no existence of ethical problems in humanity [38]. Inside organizations, ethical conflicts are increasingly present given the dynamic and complex nature of human interactions, where unethical attitudes and behaviors and many of them immoral by people can bring some benefits in the short term, but will dissipate the organizations interests in the long term [10].

According to Reference [39], "The society has become more vigilant in relation to business activity and many companies were forced to reconsider the ethical conduct criteria, pressed by borderless competition and by a market with global tendencies" (p. 19). Business ethics does not refer to a specific form of ethics, but to the application of its principles in the organizations activity context, which shall encourage in their womb as well as in their external environment [38]. Reference [44] exalts that "ethical laxity in business situations may merely reflect the general value systems internalized by young people” (p. 148). Reference [45] points out that "corruption in business is as old as business itself” (p. 39), and to some extent exists almost transversally in every culture, market and country, where in certain cases turns out to be necessary for the survival of the system where people live, and in others it is condemned and criticized, but never entirely eradicated. Reference [8] calls attention for the critical role played by the organizations in society and in the economy, while ethical and unethical conduct stages, since they are imbued entities with human activity which have a preponderant impact on individual behavior of who integrates and involves them. Reference [46] refers the top managers, in order to implement significant improvements, must implement and enforce the ethical policy of organizations. The belief that unethical behavior is prominent in business world and at work in general, can in fact lead to such behaviors [12]. Ethics in the workplace has been linked with a number of counterproductive behaviors with financial impact for organizations, such as absenteeism, non-quality costs, sabotage, theft, deliberate loss of time, aggression, and inside trading, in other words, issues relating to illegality, immorality and behavioral deviation [47]. When individuals who violate confess their irregularities, often cite as justification for their actions a belief that the unethical behavior was a necessary prerequisite for success, in a world somewhat few or nothing ethical [48]. These people be- 
lieve that in order to compete, their own ethical standards must compromised [11,48]. Furthermore, individuals often tend to believe, erroneously, that they are ruled by ethical standards higher than their peers $[48,49]$. Frequently, many of these "transgressors" say specifically that the others around them are involved in much worse unethical actions [48,50,51].

Ethics is also a predictor factor of labour performance within the reach of success [51] and job satisfaction [52], also contributing to greater life satisfaction [35]. Results suggest that infringers, or those with a deviation tendency from the right conduct, may be motivated to engage in unethical activities simply because they want to achieve success, or by the need to compete among the workplace context, since, often they compete with individuals who adopt these kind of conducts, ending by resorting to such behaviors $[11,47,50]$. Exhibitions carried out by the media in recent times, have issued certain confessions of certain offenders of some kind of customs and rules, as acts committed using unethical conducts by the fact that the perception of the need for such conduct to obtain personal or organizational success [47]. Clearly, the specific ethical standards of each individual will be well related to perceptions of unethical practices are necessary precursors to success [48]. Other potential factors to predict the perception of the role of Ethics and the success may include emotional intelligence [53] and selfesteem $[47,50]$.

\subsection{Ethics and Emotional Intelligence}

To the extent that ethical conduct perception is based on own and others behaviors understanding, and in empathetic capacity towards others, emotional intelligence is closely related to ethics and success perceptions, and is expected to be less probable that emotionally intelligent individuals once are less likely to believe that others are not ethical and being themselves more ethical, should behave without ethics to succeed [13]. Still according to Reference [13] it is expected that this relationship is mediated by self-esteem. Specifically, individuals with high levels of EI are often more successful in their interactions with others, achieving desired results, due to its competitive advantage in adaptability to the recognition and use of emotion and emotion-focused behaviors [1,53], contributing to the a higher self-esteem development [54]. In addition, persons who have a higher self-esteem, have a greater awareness of their own value and competence, and are more likely to believe that they can achieve success at their own risk [13]. A high self-esteem has a hedonic function and general well-being in the life of each individual with beneficial effects in the respect that each one has for himself in life and about the future [55]. According to Reference [13] the research suggests that individual ethicality, perceptions of others ethicality, self- esteem and emotional intelligence are correlated with the perceptions of unethical behavior being necessary for success.

Ethics emerges closely related to success. Intelligence, and specifically Emotional Intelligence, also shows a deep connection to organizational success, therefore, more and more in addition to the types of knowledge, skills and traditional abilities associated to individual performance and work success, personal configuration skills are required, such as, personal management, empathy and interpersonal sensitivity, that is, a set of skills that to achieve the required success, deal with the recognition, regulation and emotional expression-emotional competencies [53]. According to Reference [56], in business environment "the use of emotion can be genuine or simply a tactic to achieve the objectives pursued" (p. 15), being ethically more acceptable the premeditated use of emotions as tactic with greater ethical tolerance in use of positive emotions than negative emotions, than other types of dissimulation strategies, like the use of false information or failure to comply promises.

Reference [6] exalts that emotions are intrinsic to a rational process of ethical decision-making, and currently in organizations and in the media itself, the ethical issues are often discussed emotionally. Ethics is inextricably linked to emotion and consequently to emotional intelligence. Organizational climate and culture have the ability to promote in their workers emotional states with direct influence on their ethical decisions. Although emotion and ethics theory is not yet conveniently established, any research in ethics should have no continuation isolated from the emotional factor [6].

In order to test the hypotheses of this research and to compare the results with previous investigations was assumed the Reference [13] methodology.

\section{Methodology}

\subsection{Research, Approach and Procedure}

The conceived and used observation and data collection instrument in this study was the questionnaire. A pre-test with 10 participants was conducted before its submission to answer. After reviewing the structure and checked all the questions, we proceeded to send it to answer. The empirical study was conducted in a first phase by sending the questionnaire in the period from July 18 to July 24, 2011. Subsequently we proceeded to its forwarding to all non-respondents on July 25, 2011, expunging all respondents. In total, on August 5, 2011, from a group of 6371 exporting companies and/or with interest in exporting of the Agency for Investment and External Commerce of Portugal (AICEP) database, 625 answers were obtained, with a total of 404 valid responses for analysis. The non-response bias did not constitute a 
problem in data analysis according with the extrapolation method of Reference [57], since there was no significant differences for $\mathrm{p}>0.05$ between the values of the first ( $\mathrm{n}$ $=101)$ and last $(\mathrm{n}=101)$ quartiles of respondents. So, were not found significant differences between those who responded to the questionnaire before and after his forwarding. Companies' contacts (e-mail) were collected on: http://www.portugalglobal.pt/PT/Internacionalizar/. The questionnaire application was accompanied by their filling instructions and a study objectives presentation. Participants were asked to respond the survey the most sincerely as possible, were assured of anonymity existence and data confidentiality, and in case of interest in getting the results had the possibility to indicate an e-mail for sending. It was also pointed the voluntary nature of participation. The data collection process was performed automatically, hosting the questionnaire in an internet domain of the Faculty of Economics, University of Coimbra, consolidating all information in digital format for subsequent export and statistical analysis in SPSS, version "IBM SPSS Statistics 19" and Microsoft Office Excel. The non-duplication of response was also assured with the creation of a code for each company. The companies were contacted by e-mail where was attached the link of the questionnaire, created and managed by the tool "Lime Survey". The research key variables are Emotional Intelligence (EI), Individual Ethics (IE), Perceptions of Others Ethics (POE), Ethics and Success Perceptions (ESP) and Self-Esteem (SE). The Social Desirability (SD), the biographical variables Age and Gender, and organizational variables Economic Activities Classification (EAC), number of Employees (NE), Turnover of last year (T) and Exports Percentage (EXP) are control variables.

Sample revealed that $48 \%$ of those surveyed industry representatives are male and 52\% female, with ages varying between 21 and 90 years, with an average of 42, 27 years. In order to weave the sample characterization with the organizational variables and because they were not mandatory, have refined the data through the elimination of 223 answers-missing values, considering 281 valid responses. The verified number of employees' average of the surveyed companies was 105 , with a maximum of 5000 and a minimum of 1 . With regard to the percentage of export, the minimum found was $0 \%$ of companies that have not exported despite the interest to do so, or that in the last year have not sold abroad, and a maximum of $100 \%$ in purely export companies. The observed average of exports was $40 \%$, in a sample of companies with an average turnover of 39,680,291 $€$.

\subsection{Hypotheses}

The hypotheses formulation follows the research of Reference [13]. The hypotheses 1 and 2 study the EI, Ethics and Ethics Perceptions. EI will be correlated with Ethics, and emotionally intelligent individuals will be more skilled at deciphering the others behaviors, ethical or unethical. In what concerns about the involvement in unethical behaviors, being EI correlated with Ethics, people with higher skills of emotional comprehension, control and utilization, will be more capable to not engage in unethical conduct. Accordingly, it is proposed hypothesis 1 :

*Hypothesis 1: Emotional intelligence is correlated with individual ethicality, such that high EI individuals will report engaging in fewer unethical behaviors than low EI individuals.

With regard to POE, EI contributes to a better discern ability of others ethical behaviors, and it seems that individuals with high EI levels will be more likely to not draw a negative ethical profile of their peers such as those that exhibit lower EI levels. So the hypothesis 2 suggests:

Hypothesis 2: Emotional intelligence is correlated with perceptions of others' ethicality, such that low EI individuals perceive others as more unethical than high EI individuals.

Hypothesis 3 studies EI and Ethics Perceptions, where EI will not only contribute to understand POE, but, also to know the discrepancy between themselves and others ethical perceptions. Emotionally intelligent individuals will be more accurate in evaluating Ethics, those that exhibit lower levels. Then the hypothesis 3 suggests:

"Hypothesis 3: Emotional intelligence will explain incremental variance in perceptions of others' ethicality, over and above individual ethicality.

The fourth hypothesis suggests that the interaction between IE and EI will explain the difference between the own and others ethical perception. Individuals with high levels of EI and IE will evaluate others ethics in a fairer manner, and closer to their own ethical characteristics, than individuals with low levels of EI and IE. It is expected that EI does not only explain incremental variance in POE, but interact with IE in prediction of POE. So, it is assumed the difference between the IE and POE will be higher in individuals with low levels of EI than on emotionally intelligent individuals, suggesting the hypothesis 4:

Hypothesis 4: Emotional intelligence will impact the degree of discrepancy between individual ethicality and perceptions of others' ethicality, such that high EI individuals will report less discrepancy between self and other ethicality than low EI individuals.

Normative pressures performed by group norms, especially those that support illegal or unethical behaviors, and pressures performed by co-workers, are very influent in the group and individual decision [58]. Many "transgressors" think that others engage in much worse un- 
ethical actions [50,51], then, the 5 hypothesis suggests:

Hypothesis 5: Individuals' self-reported unethical behaviors are correlated with their perceptions of the unethical behaviors of others, such that the more likely an individual is to engage in an unethical practice, the more likely they believe others are doing the same.

Individuals tend to mistakenly believe that they are more ethical than their peers $[12,48,49]$, then, the hypothesis 6 suggests:

Hypothesis 6: Individuals perceive themselves to be more ethical than their counterpart others. Self-reported tendency to engage in unethical behaviors will reflect a greater degree of ethicality than perceptions of others' ethics.

The hypothesis 7 and hypothesis 8 refers to ethical conduct and facilitation of success. Since the ethics perception is based on own and others behaviors understanding and in empathic capacity toward others, EI is related to ethics perceptions relatively to success. It is expected to be less probable believe that emotionally intelligent individuals, who are less likely to believe that others are not ethical and being them more ethical, behave unethically to achieve success. Thus the hypothesis 7 suggests:

Hypothesis 7: Individual ethicality, perceptions of others' ethicality, self-esteem, and emotional intelligence will correlate with perceptions unethical behavior facilitates success, such that the higher an individual's ethicality, self-esteem, and perceptions of others' ethicality, the less likely they will perceive unethical behavior is necessary for success.

It is suggested the relationship between EI and ESP is mediated by SE in a way that emotionally intelligent individuals will have a lower probability to realize that unethical behavior facilitates success due to their higher self-esteem. So, the hypothesis 8 suggests:

"Hypothesis 8: Self-esteem will mediate the relationship between EI and ethics and success perceptions.

"[Each of these hypotheses is derived on 4 partial hypotheses where EI is substituted for each of its 4 subdimensions, SEA (Self-Emotion Appraisal), OEA (Others Emotion Appraisal), UOE (Use of Emotion) and ROE (Regulation of Emotion), testing the global and partial hypothesis].

\subsection{Measures Used}

The first part of questionnaire structure, subdivided into four parts relating to the four branches of EI of Reference [5] and Reference [7], seeks to obtain information to assess the respondents' level of EI through the use of Wong and Law Emotional Intelligence Scale of Reference [37]. The part I a) makes questions to proceed to the measurement of the first branch-self-emotion appraisal; part I b) to the second branch—others emotion appraisal; part I c) for the third branch—use of emotion and part I d) for the fourth branch-regulation of emotion. In the second part, it is intended to capture the ethical behavior level of each respondent, using the adapted 6 items scale by Reference [40] of the original scale to measure individual ethical behavior developed by Reference [46]. The third part seeks to measure the POE of each respondent. The participants' perceptions about others ethicality were evaluated with the same criteria and items used in the IE scale, only with the change of reference. Participants were asked to assess their perceptions based on the experience about others ethicality. The questionnaire part IV assesses the perceptions of the ethics role in the success of each participant through a 6 items scale, adapted from Reference [51] scale. In the fifth part, using the SE measuring scale of Morris Rosenberg, it is intended to assess its level in the respective sample. It was used the "adjustment by José Pedro Leitão Ferreira (2001), Faculty of Sport Sciences and physical education of the University of Coimbra from the Rosenberg Self-Esteem Scale developed by Morris Rosenberg (1965)" in appendix I of Reference [59]. Part VI intended to measure the $\mathrm{SD}$ variable, that is, the socially desirable response tendency, using for this purpose the 33 items of social desirability scale of Reference [60]—Marlowe-Crowne Social Desirability Scale (MCSDS). All items of the questionnaire were subjected to a 4 points response scale Likert-Type (4 = "SA—strongly agree", 3 = "A—agree", 2 = "D-disagree" and "SD - 1 = strongly disagree"), and mandatory. Finally, the seventh and eighth parts of the questionnaire required the filling of not mandatory fields, consigned to biographical data, age and gender, and organizational, EAC, NE, T and EXP.

\section{Results}

Collected and prepared the data, was proceeded to the variables treatment, performing an exploratory factorial analysis for each of the measures. Table 1 specifies the values for the mean and standard deviation, and the performed factorial analysis summary. The total scale of EI did not show internal consistency problems, since the Cronbach's Alpha displays a value of 0.859 . Through the factorial analysis were found the 4 factors corresponding to the underlying sub-dimensions of the EI construct. This result is consistent with the literature [37]. The total measure of EI construct was calculated through the 4 sub-dimensions arithmetic mean, obtaining the overall index according to the research procedure of Reference [13]. Results indicated that the IE scale items load to a single factor and the coefficient Alpha for this scale was 0.716. It was computed a totalizer index of the scale through the arithmetic mean of 6 the variables according to Reference [61] and Reference [13]. The same procedure was adopted on the POE measuring scale, where 
Table 1. Factorial analysis and descriptive analysis of variables and scales.

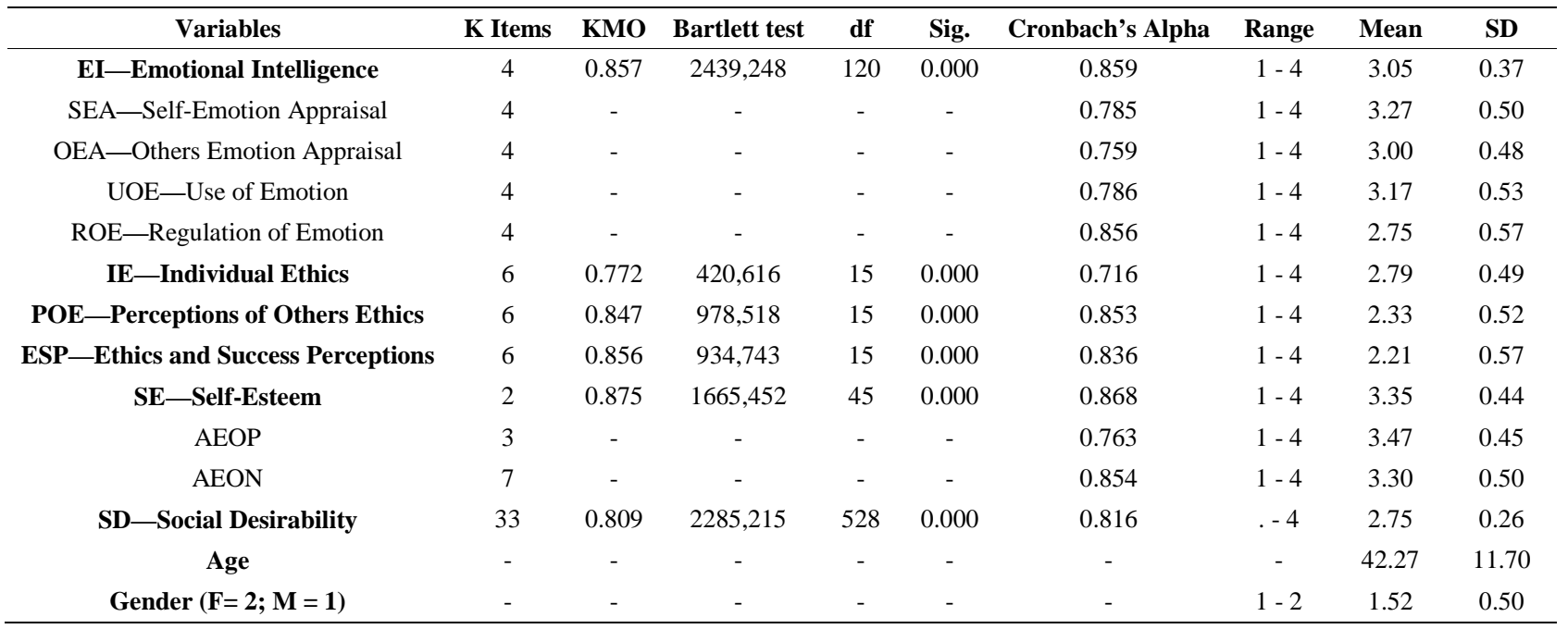

the results indicated that the items load to a single factor with a coefficient Alpha of 0.853 , revealing a good reliability. On the ESP measurement scale, the results indicated that the items load to a single factor and with a coefficient Alpha of 0.836 , revealing a good reliability. The scale totalizer index was also computed by the arithmetic mean of the 6 items. The SE total scale does not show internal consistency problems, since the Cronbach's Alpha exhibited a value of 0.868 , revealing its good nature. Were found 2 scale factors one with positive orientation, and the other with negative orientation. The correlation between the two factors were more than sufficient and consistent to allow the use of the measure total score, computed by the arithmetic mean of its 10 items. The result of SD scale internal consistency analysis is good, because indicates a coefficient Alpha of 0.816. It was used the total index scale that reflects the 33 items arithmetic mean. The factorial analysis proved to be uninterpretable. It should be noted that the scale authors do not provided any evidence of the construct factorial structure, and several studies report the failure of MCSDS factorial analysis, where typically the researchers that use this scale utilize the total score, calculated through its 33 items [62].

As the sample under study is higher than 30, namely, 404 companies, according to Reference [63] the distribution of the sample mean is considered normal. Models do not have multicollinearity problems, as in the correlation matrix in Table 2 there are no correlations with absolute values exceeding 0.75 according to Reference [61]. By Reference [63] the observed VIF values (Variance Inflaction Factor) in the constructed models for the regression coefficients $\beta$ and the T tolerance values validate the non-existence of multicollinearity problems, implying the stability in the regression coefficients magnitude and sign. The prerequisites of normality, of ho- moscedasticity and independence of errors were checked on models, allowing the relation analysis between the dependent and independent variables, according to Reference [63].

In Table 2 emerges an important and meaningful result of the line that conducted the study. The significant correlation between EI and IE $(r=0.278$, $p<0.01)$, and between EI and POE ( $r=0.196, p<0.01)$. The higher EI levels of an individual, the higher ethical behavior level and the higher others ethical behavior level perceived. As expected, SD responses are correlated with IE and POE responses, so that, the bigger the tendency of an individual responding with a socially desirable direction the less is the propensity to report own unethical behavior trends ( $r=0.440, p<0.01)$ and perceptions of others engage in unethical behaviors $(r=0.251, p<0.01)$. The Pearson correlation coefficients closer to 1 or -1 , the highest is the variable variation percentage that is explained by another variable, in the same direction or in the opposite direction, and the more close to zero, the lower explained percentage [61]. As the IE and POE scales assess the propensity to engage in unethical behaviors, once the scores are reversed analyses the individual ethical behavior and the perceptions of others ethicality. So, when IE correlates to SD, correlates in a positive way for that very reason, showing that the greater the tendency of an individual responding with a socially desirable direction, the lower is the propensity to report unethical behavioral trends and the greater the propensity to report ethical behaviors ( $r=0.440, p<0.01$ ). In POE, the greater the tendency for an individual to respond with a socially desirable direction, the lower is the propensity to report unethical behaviors in others and the greater is the reporting of ethical behaviors in their peers $(r=0.251$, $p<$ 0.01). Social Desirability was retained as a control variable in subsequent analyses as necessary. 
Table 2. Descriptive statistics and correlations for key study variables $(\mathrm{N}=404)$.

\begin{tabular}{|c|c|c|c|c|c|c|c|c|c|}
\hline Variables & Mean & SD & EI & IE & POE & ESP & SE & SD & Age \\
\hline EI—Emotional Intelligence & 3.05 & 0.37 & 1 & & & & & & \\
\hline IE—Individual Ethics & 2.79 & 0.49 & $0.278^{* *}$ & 1 & & & & & \\
\hline POE-Perceptions of Others Ethics & 2.33 & 0.52 & $0.196^{* *}$ & $0.421^{* *}$ & 1 & & & & \\
\hline ESP_Ethics and Success Perceptions & 2.21 & 0.57 & $-0.357^{* *}$ & $-0.447^{* *}$ & $-0.447^{* *}$ & 1 & & & \\
\hline SE—Self-Esteem & 3.35 & 0.44 & $0.579^{* *}$ & $0.247^{* *}$ & 0.093 & $-0.278^{* *}$ & 1 & & \\
\hline SD_Social Desirability & 2.75 & 0.26 & $0.576^{* *}$ & $0.440^{* *}$ & $0.251^{* *}$ & $-0.352^{* *}$ & $0.515^{* *}$ & 1 & \\
\hline Age & 42.27 & 11.70 & 0.088 & $0.093^{* *}$ & $0.155^{* *}$ & -0.066 & 0.013 & $0.169^{* *}$ & 1 \\
\hline
\end{tabular}

${ }^{* *}$ Significant Correlation at level 0.01 (2-tailed).

In Table 3 are presented the partial correlations between IE, POE, SE, EI and ESP, with the respective impact removal of SD. Although the zero-order Pearson correlations indicate a statistically significant correlation between EI and IE and also with POE, when the effect of socially desirable responding is removed from these correlations, a non-significant relationship emerges. The partial correlation coefficients for having a variable under control have the same assumptions of zero order coefficients, where it joins the need for linear relationship between the controlled variable and the others, and normal distribution of controlled variable [61]. These assumptions are verified. In fact, when this effect is removed, the correlation of EI with IE passes to $(r=0.034$, $\mathrm{p}<0.01)$ and with POE $(\mathrm{r}=0.065, \mathrm{p}<0.01)$. Then just $0.1 \%$ of the variance in IE and $0.4 \%$ of the variance in POE are explained by EI. This result indicates that if individuals do not respond according to what is socially accepted, more easily report their involvement in unethical behaviors and more easily perceive that others also have unethical conduct. Should be noted another result also explanatory of the SD power response on the correlation between SE and IE. However, while the zero-order correlation exhibited statistical significance $(r=0.247$, $p$ $<0.01$ ), when removing the SD response effect, it is verified that an individual with higher SE is less likely to report ethical behaviors which would report with SD response, showing a negative relationship of SE with IE $(\mathrm{r}=-0.027, \mathrm{p}<0.01)$.

Through the hypotheses 1 and 2 EI would be correlated with the IE and POE. These hypotheses were tested using linear regression analysis, controlling the SD responding effects, which results are reported in Table 4. The models proved to be statistically significant as can be seen in the next table.

Hypothesis 1-Regression model:

$$
I E_{i}=\beta_{0}+\beta_{1} E I_{i}+\beta_{2} S D_{i}+u_{i} \text { with } i=1, \cdots, 404 .
$$

Hypothesis 2-Regression model:

$$
P O E_{i}=\beta_{0}+\beta_{1} E I_{i}+\beta_{2} S D_{i}+u_{i} \text { with } i=1, \cdots, 404 \text {. }
$$

By hypothesis 1 test results, the adjusted $\mathrm{R}^{2}=0.190$, allowing to say that $19 \%$ of the IE total variance is explained by SD. The SD variable exerts a positive effect by presenting a standardized regression coefficient and statistically significant on the dependent variable IE $(\beta=$ $0.418, t=7.621, p<0.05$ ), in which the self-reported ethical behaviors increases 0.418 standard deviations for every increase of one standard deviation in social desirability. Emotional Intelligence has not revealed a relevant relative contribution ( $\beta$ ), therefore not influencing significantly the ethical behavior.

The hypothesis 2 test results show that $6.2 \%$ of the POE total variance is explained by $\mathrm{SD}$, which exerts a positive effect on POE $(\beta=0.207, \mathrm{t}=3.507, \mathrm{p}<0.05)$. As the desire for social acceptance increases, individuals tend to report that others adopt ethical conducts. EI has not revealed a relevant relative contribution $(\beta)$, not influencing statistically POE in a significant way. Were performed linear regressions to test the partial hypotheses of hypotheses 1 and 2, where EI gave place to its 4 subdimensions, whose results are in the Table 5.

The following equations represent the respective regression models:

Partial hypothesis 1-Regression model:

$$
\begin{aligned}
I E_{i} & =\beta_{0}+\beta_{1} E I_{-} S E A_{i}+\beta_{2} E I_{-} O E A_{i} \\
& +\beta_{3} E I \_U O E_{i}+\beta_{4} E I_{-} R O E_{i} \\
& +\beta_{5} S D_{i}+u_{i} \text { with } i=1, \cdots, 404 .
\end{aligned}
$$

Partial hypothesis 2-Regression model:

$$
\begin{aligned}
P O E_{i}= & \beta_{0}+\beta_{1} E I_{-} S E A_{i}+\beta_{2} E I_{-} O E A_{i} \\
& +\beta_{3} E I_{-} U O E_{i}+\beta_{4} E I_{-} R O E_{i} \\
& +\beta_{5} S D_{i}+u_{i} \text { with } i=1, \cdots, 404 .
\end{aligned}
$$

From the partial hypotheses 1 test results could be said that $20 \%$ of the IE total variance is explained by EI SEA and SD. The variables EI_SEA and SD have a positive effect on the dependent variable IE $(\beta=, \mathrm{t}=0.135$ $2.534, \mathrm{p}<0.05)$ and $(\beta=0.435, \mathrm{t}=7.862, \mathrm{p}<0.05)$ respectively. Indeed, the expected self-reported ethical behavior increases 0.135 standard deviations for each standard deviation increment in self-emotion appraisal, and 0.435 standard deviations for each standard deviation 
Table 3. Partial correlations between key study variables removing the effects of SD $(N=404)$.

\begin{tabular}{cccccc}
\hline Variables & EI & IE & POE & ESP & SE \\
\hline EI-Emotional Intelligence & 1 & & & & \\
IE-Individual Ethics & 0.034 & 1 & & & \\
POE-Perceptions of Others Ethics & 0.065 & $0.358^{* *}$ & 1 & & \\
ESP-Ethics and Success Perceptions & $-0.202^{* *}$ & $-0.347^{* *}$ & $-0.396^{* *}$ & $-0.120^{*}$ & 1 \\
SE-Self-Esteem & $0.404^{* *}$ & -0.027 & -0.044 & & \\
\hline
\end{tabular}

** Significant Correlation at level 0.01; ${ }^{*}$ Significant Correlation at level 0.05 .

Table 4. Regression results for the role of emotional intelligence in IE and POE.

\begin{tabular}{|c|c|c|c|c|c|}
\hline & & \multicolumn{2}{|c|}{ IE-Individual Ethicality } & \multicolumn{2}{|c|}{ POE-Perceptions of Others Ethics } \\
\hline Variables & & $\beta$ & $t$ & $\beta$ & $t$ \\
\hline SD—Social Desirability & & $0.418^{* *}$ & 7.621 & $0.207^{* *}$ & 3.507 \\
\hline \multirow[t]{5}{*}{ EI—Emotional Intelligence } & & 0.037 & 0.682 & 0.077 & 1.306 \\
\hline & Total $\mathrm{R}^{2}$ & \multicolumn{2}{|c|}{0.194} & \multicolumn{2}{|c|}{0.067} \\
\hline & Total $\mathrm{R}^{2}$ Adjusted & \multicolumn{2}{|c|}{0.190} & \multicolumn{2}{|c|}{0.062} \\
\hline & F Test & \multicolumn{2}{|c|}{48.290} & \multicolumn{2}{|c|}{14.428} \\
\hline & Sig. & \multicolumn{2}{|c|}{0.000} & \multicolumn{2}{|c|}{0.000} \\
\hline
\end{tabular}

Note: $\mathrm{N}=404 ;{ }^{* *} \mathrm{p}<0.05 ;$ All regression coefficients $\beta$ are standardized.

Table 5. Regression results for the role of emotional intelligence 4 sub-dimensions in IE and POE.

\begin{tabular}{|c|c|c|c|c|}
\hline \multirow[b]{2}{*}{ Variables } & \multicolumn{2}{|c|}{ IE-Individual Ethicality } & \multicolumn{2}{|c|}{ POE-Perceptions of Others Ethics } \\
\hline & $\beta$ & $t$ & $\beta$ & $t$ \\
\hline SD—Social Desirability & $0.435^{* *}$ & 7.862 & $0.205^{* *}$ & 3.408 \\
\hline (EI)_SEA-Self-Emotion Appraisal & $0.135^{* *}$ & 2.534 & n.s. & \\
\hline (EI)_OEA—Others Emotion Appraisal & \multicolumn{2}{|l|}{ n.s. } & \multicolumn{2}{|l|}{ n.s. } \\
\hline (EI)_UOE-Use of Emotion & \multicolumn{2}{|l|}{ n.s. } & \multicolumn{2}{|l|}{ n.s. } \\
\hline (EI)_ROE—Regulation of Emotion & n.s. & & n.s. & \\
\hline Total $\mathrm{R}^{2}$ & \multicolumn{2}{|c|}{0.210} & \multicolumn{2}{|c|}{0.069} \\
\hline Total $\mathrm{R}^{2}$ Adjusted & \multicolumn{2}{|c|}{0.200} & \multicolumn{2}{|c|}{0.057} \\
\hline F Test & \multicolumn{2}{|c|}{21.134} & \multicolumn{2}{|c|}{5.894} \\
\hline Sig. & \multicolumn{2}{|c|}{0.000} & \multicolumn{2}{|c|}{0.000} \\
\hline
\end{tabular}

Note: $\mathrm{N}=404 ;{ }^{* *} \mathrm{p}<0.05$; All regression coefficients $\beta$ are standardized; n.s. - not significant.

increment in social desirability.

The partial hypothesis 1 that suggests the individual ability to evaluate own emotions exert a positive influence on ethical behavior with the social desirability response control is supported. Emotional Intelligence Self-Emotion Appraisal is correlated with Individual Ethicality, to the extent that individuals who better assess their own emotions will present a much smaller involvement in unethical behaviors and a larger involvement in ethical behaviors than those with low levels of emotional evaluation, since, when increases EI_SEA increases IE and vice versa. Hypothesis 1 is partially corroborated.
In the regression model that tested the hypothesis 2 partial hypotheses, $5.7 \%$ of total POE variability is explained by $\mathrm{SD}$, which exerts a statistically significant positive effect on POE $(\beta=0.205, \mathrm{t}=3.408, \mathrm{p}<0.05)$. The multiple linear regression analysis results suggest that there is no significant evidence to corroborate the hypothesis 2 and accordingly its partial hypotheses, under which the EI sub-dimensions SEA, OEA, UOE and ROE would perform influence over POE. Hypothesis 2 is not corroborated.

In the hypothesis $\mathbf{3}$ and its partial hypotheses was predicted that EI would explain incremental variance in POE over and above IE. 
These hypotheses were tested through a hierarchical regression analysis, which results are presented in Table 6 . In the first step, POE as dependent variable was regressed on IE and SD (control variable). In the second step, the variables corresponding to the EI subdimensions (SEA-Self-Emotion Appraisal, OEA-Others Emotion Appraisal, UOE-Use of Emotion and ROE-Regulation of Emotion) were introduced.

$$
\begin{aligned}
& \text { Hypothesis } 3 \text { and Partial hypothesis } 3 \\
& \text { Hierarchical Regression } \\
& \text { Regression model-Step 1: } \\
& \quad P O E_{i}=\beta_{0}+\beta_{1} S D_{i}+\beta_{2} I E_{i}+u_{i} \text { with } i=1, \cdots, 404 \text {. }
\end{aligned}
$$

Regression model-Step 2:

$$
\begin{aligned}
P O E_{i} & =\beta_{0}+\beta_{1} S D_{i}+\beta_{2} I E_{i}+\beta_{3} E I_{-} S E A_{i} \\
& +\beta_{4} E I_{-} O E A_{i}+\beta_{5} E I_{-} U O E_{i} \\
& +\beta_{6} E I_{-} R O E_{i}+u_{i} \text { with } i=1, \cdots, 404 .
\end{aligned}
$$

By the regression model was observed that $17.6 \%$ of POE total variance is explained by IE. Individual Ethicality has a significant positive effect on $\operatorname{POE}(\beta=0.421$, $\mathrm{t}=9.317, \mathrm{p}<0.05)$. With the introduction of EI subdimensions there was a significant change $\left(R^{2}=0.187\right.$, $\left.\Delta \mathrm{R}^{2}=0.009\right)$ also visible by $\mathrm{R}^{2}$ adjusted at $\mathrm{p}<0.05$ level $\left(\mathrm{R}_{\mathrm{a}}^{2}=0.183, \Delta \mathrm{R}_{\mathrm{a}}^{2}=0.007\right)$, indicating that EI in its sub-dimension Regulation of Emotion added a significant incremental variation in POE. Emotional Intelligence has a significant positive effect over POE $(\beta=$ $0.401, \mathrm{t}=8.710, \mathrm{p}<0.05)$, as well as the EI_ Regulation of Emotion $(\beta=0.100, t=2.167, p<0.05)$. The obtained results in the hierarchical regression analysis suggest that there is no statistically significant evidence to corroborate all partial hypotheses of hypothesis 3 according to which the EI sub-dimensions SEA, OEA and UOE would exert influence on POE. However, the hypothesis that predicted that the Regulation of Emotion would contribute to explain incremental variance in POE over and above IE is corroborated, implying this result that hypothesis 3 is partially corroborated.

Hypothesis 4 and respective partial hypotheses predicted EI would moderate the relationship between IE and POE, in such a way that the difference between these two variables would be greater for low EI individuals than for high EI individuals.

Hypothesis 4 and Partial hypothesis 4

Moderated Regression

Regression model-Step 1:

$I E_{i}-P O E_{i}=\beta_{0}+\beta_{1} S D_{i}+\beta_{2} I E_{i}+u_{i}$ with $i=1, \cdots, 404$.

\section{Regression model-Step 2:}

$$
\begin{aligned}
I E_{i}-P O E_{i}= & \beta_{0}+\beta_{1} S D_{i}+\beta_{2} I E_{i}+\beta_{3} E I_{-} S E A_{i} \\
& +\beta_{4} E I \_O E A_{i}+\beta_{5} E I_{-} U O E_{i} \\
& +\beta_{6} E I_{-} R O E_{i}+u_{i} \text { with } i=1, \cdots, 404 .
\end{aligned}
$$

\section{Regression model-Step 3:}

$$
\begin{aligned}
& I E_{i}-P O E_{i}=\beta_{0}+\beta_{1} S D_{i}+\beta_{2} I E_{i} \\
& +\beta_{3} E I \_S E A_{i}+\beta_{4} E I \_O E A_{i} \\
& +\beta_{5} E I_{-} U O E_{i}+\beta_{6} E I \_R O E_{i} \\
& +\beta_{7}\left(E I_{i} \times I E_{i}\right)+u_{i} \text { with } i=1, \cdots, 404 .
\end{aligned}
$$

To test this hypothesis was used a three-step moderated linear regression analysis according to the followed methodological line of Reference [13]. In the first step were added the control variable SD and the independent variable IE. In the second step was added the potential moderator variable EI, and the multiplicative term in the third step, in order to capture the interaction between EI and IE (EI $\times$ IE) according to Reference [64], Reference [63]. The tests to analyze moderators' effects are usually performed through hierarchical regressions [65]. The difference between IE and POE reports was calculated by the indicator (IE-POE), used as dependent variable in the moderated regression analysis. Results are presented in Table 7. As observed IE exerts a statistically significant positive effect $(\beta=0.534, t=11.116, p<0.05)$ and $(\beta=$ $0.530, \mathrm{t}=10.916, \mathrm{p}<0.05)$ in the 1 st and 2nd equation respectively, over the dependent variable (IE-POE). Results show that hypothesis 4 and respectively partial hypotheses are not corroborated. Emotional Intelligence did not explain any significant incremental variation in $\mathrm{R}^{2}$ in the difference between the perception of IE versus $\mathrm{POE}$, and in the third step, the $\beta$ referring to the multiplicative term $(\mathrm{EI} \times \mathrm{IE})$ was not statistically significant, which implies according to Reference [63] that the EI moderator effect is not verifiable in this sample. In these research areas according to Reference [63] the effect of context plays an important role in the modification of the dependent variable response against the independent. Somehow this effect could be latent in EI, IE and POE response, not allowing the achieving of conjectured results. Another effect that attention should be given in these circumstances is the redundancy effect [65]. As can be verified in Table 2, EI and IE exhibit a strong positive correlation ( $r=0.278, \mathrm{p}<0.01)$, leading to as stated by Reference [65] the loss of parsimony in difference explanation between IE and POE. It is clear that it's only the individual ethical level of each person that explains the verified difference between the own perceived ethical level and the perceived ethical level of others.

In hypothesis $\mathbf{5}$ was analyzed the correlation between IE and POE. Subsequently, correlations were measured by removing the SD response effects. This hypothesis predicted a correlation between IE and POE, in such a way that the self-reported tendency in unethical behavior involvement would correspond to a greater perception that others also would practice those same behaviors. In 
Table 6. Hierarchical regression results for POE.

\begin{tabular}{|c|c|c|c|c|c|}
\hline & Step 1 & & Step 2 & & \\
\hline Variables & $\beta$ & $t$ & $\beta$ & & $t$ \\
\hline SD—Social Desirability & n.s. & & n.s. & & \\
\hline IE-Individual Ethics & $0.421^{* *}$ & 9.317 & $0.401^{* *}$ & & 8.710 \\
\hline (EI)_SEA—Self-Emotion Appraisal & - & & n.s. & & \\
\hline (EI)_OEA—Others Emotion Appraisal & - & & n.s. & & \\
\hline (EI)_UOE-Use of Emotion & - & & n.s. & & \\
\hline (EI)_ROE—Regulation of Emotion & - & & $0.100^{* *}$ & & 2.167 \\
\hline Total $\mathrm{R}^{2}$ & \multicolumn{2}{|c|}{0.178} & \multicolumn{3}{|c|}{0.187} \\
\hline Total $\mathrm{R}^{2}$ Adjusted & \multicolumn{2}{|c|}{0.176} & \multicolumn{3}{|c|}{0.183} \\
\hline$\Delta \mathrm{R}^{2}$ & \multicolumn{2}{|c|}{-} & \multicolumn{3}{|c|}{0.009} \\
\hline$\Delta \mathrm{R}^{2}$ Adjusted & \multicolumn{2}{|c|}{-} & \multicolumn{3}{|c|}{0.007} \\
\hline F Test & \multicolumn{2}{|c|}{86.807} & \multicolumn{3}{|c|}{46.151} \\
\hline Sig. & \multicolumn{2}{|c|}{0.000} & \multicolumn{3}{|c|}{0.000} \\
\hline
\end{tabular}

Note: $\mathrm{N}=404 ;{ }^{* *} \mathrm{p}<0.05$; All regression coefficients $\beta$ are standardized; n.s. - not significant.

Table 7. Moderated regression analysis results for ei as a potential moderator of IE and POE discrepancy.

\begin{tabular}{|c|c|c|c|c|c|c|}
\hline & \multicolumn{2}{|l|}{ Step 1} & \multicolumn{2}{|c|}{ Step 2} & \multicolumn{2}{|l|}{ Step 3} \\
\hline Variables & $\beta$ & $t$ & $\beta$ & $t$ & $\beta$ & $t$ \\
\hline SD—Social Desirability & n.s. & & n.s. & & n.s. & \\
\hline IE—ndividual Ethics & $0.534^{* *}$ & 11,116 & $0.530^{* *}$ & 10.916 & n.s. & \\
\hline (EI)_SEA-Self-Emotion Appraisal & - & & n.s. & & n.s. & \\
\hline (EI)_OEA—Others Emotion Appraisal & - & & n.s. & & n.s. & \\
\hline (EI)_UOE-Use of Emotion & - & & n.s. & & n.s. & \\
\hline (EI)_ROE_-Regulation of Emotion & - & & n.s. & & n.s. & \\
\hline $\mathrm{EI} \times \mathrm{IE}$ & - & & - & & n.s. & \\
\hline Total $\mathrm{R}^{2}$ & \multicolumn{2}{|l|}{0.254} & \multicolumn{2}{|c|}{0.259} & \multicolumn{2}{|l|}{0.262} \\
\hline Total $\mathrm{R}^{2}$ Adjusted & \multicolumn{2}{|l|}{0.250} & \multicolumn{2}{|c|}{0.248} & \multicolumn{2}{|l|}{0.249} \\
\hline$\Delta \mathrm{R}^{2}$ & \multicolumn{2}{|l|}{-} & \multicolumn{2}{|c|}{0.005} & \multicolumn{2}{|l|}{0.003} \\
\hline$\Delta \mathrm{R}^{2}$ Adjusted & \multicolumn{2}{|l|}{-} & \multicolumn{2}{|c|}{-0.002} & \multicolumn{2}{|l|}{0.001} \\
\hline F Test & \multicolumn{2}{|l|}{68.344} & \multicolumn{2}{|c|}{23.138} & \multicolumn{2}{|l|}{20.042} \\
\hline Sig. & \multicolumn{2}{|l|}{0.000} & \multicolumn{2}{|c|}{0.000} & \multicolumn{2}{|l|}{0.000} \\
\hline
\end{tabular}

Note: $\mathrm{N}=404 ;{ }^{* *} \mathrm{p}<0.05$; All regression coefficients $\beta$ are standardized; n.s. - not significant.

fact, by Table 2, IE and POE correlated in ( $\mathrm{r}=0.421$, $\mathrm{p}<$ 0.01 ), indicating approximately $18 \%$ of the explained variance of a variable towards the other respectively. It should be noted that the observed relationship between these variables remains after withdrawing the SD response effects (see partial correlations Table 3; $r=0.358$, $\mathrm{p}<0.01)$. This means that $13 \%$ of the POE variance level is explained by IE levels after controlling the SD response effects. Indeed, the results corroborate the hypothesis 5 .
It can be already pointed out the fact that in this sector was observed an average value of 2.8 to the ethical behavior and an average value of 2.3 to the perception of others ethics, on a scale of 1 to 4 points, as shown in Table 1. These values present a discrepancy between the self-reported ethical behavior and the self-reported level about others engage in ethical conduct or not. This discrepancy appears in favour of self-reported ethical behavior. With this result, further will be analyzed the hypothesis 6, demonstrating the consistency and signifi- 
cance of that discrepancy.

Hypothesis 6 predicted that the tendency to answer in unethical behaviors involvement would reflect higher ethicality degree than POE self-reports. A t test was conducted to compare the IE mean with the POE mean. The observed average level of ethical behavior is 2.79 points, higher than the POE average in 0.46 points (2.79 2.33) respectively. As expected and visible in Table 8, the average of the surveyed individuals reported as being more ethical than their peers. The $t$ test with sig. $=0.000$, shows for $\mathrm{p}<0.01$, that the reported involvement in ethical behaviors by the respondents is significantly higher than the report that they made about the others involvement in ethical behaviors. The hypothesis is corroborated, showing that in this activity sector there is a strong and significant tendency to consider others less ethical. This result is consistent with the literature review, because humans tend to have a natural inclination to often consider themselves more ethical than their peers $[12,13,45,48,49]$.

Hypothesis 7 predicted the perceptions that unethical behavior facilitates success (ESP) would be correlated with IE, POE, EI and SE. Was tested by the correlations analysis between the variables reported in Table 2. Individuals who are tuned with the fact that unethical behavior is necessary for success are also more likely to report their involvement in unethical behaviors (IE) $(r=-0.447$, $\mathrm{p}<0.01$ ), therefore, high scores on ESP scale indicate a good perception that unethical behavior is a necessary precursor to success and high scores on IE scale indicate high ethical standards. Given the IE items scores reversion, the flaunted correlation by these two variables is negative. However, as this correlation is significant and with negative sign, it is concluded that individuals with high levels of IE are less likely to consider that unethical behavior is necessary for success. It is also visible, that individuals with high ESP scores, who consequently are in line with the fact that unethical behavior is necessary for success, consider that others also engage in unethical behaviors $(r=-0.447, p<0.01)$, achieve low SE scores $(\mathrm{r}=-0.278, \mathrm{p}<0.01)$ and EI $(\mathrm{r}=-0.357, \mathrm{p}<0.01)$. Indeed hypothesis 7 is corroborated.

Complementary were calculated correlations between the 4 EI sub-dimensions with the variables tested in this hypothesis. The values corroborate the hypothesis and the negative correlation seen between ESP and EI as a global construct emerges with the correlations of EI 4 sub-dimensions with ESP. Note should be made to the correlation between EI_ROE and ESP $(r=-0.308, \mathrm{p}<$ 0.01 ), from which is extracted that those who better regulate emotions, the less is the propensity to engage in unethical behaviors to achieve success. This result is consistent with the results of Reference [13], when authors state that emotionally intelligent individuals are less likely to believe that should behave without ethics to achieve success.

Hypothesis 8 and respective partial hypotheses predicted the EI impact on ESP would be mediated by SE effects, so that individuals with higher EI levels would have a greater $\mathrm{SE}$ and would be less likely to assume that unethical behavior facilitates success. This hypothesis was tested using the guidelines set out by Reference [64], with no place to hierarchical regression calculation or stepwise. According to the authors, the mediator effect is demonstrated by calculating three regression equations that establish in 1st place that the independent variable EI represents a significant variation in the mediator variable SE, with SD control. In the second equation the independent variable EI should represent a significant variation in the variable ESP. Finally, prior significant relationship between EI and ESP shall not be meaningful or even to zero with the addition of the mediator variable SE $[64,63]$. The three equations results are presented in Table 9.

Hypothesis 8 and Partial hypothesis 8

Regression model-Equation 1:

$$
\begin{aligned}
& S E_{i}=\beta_{0}+\beta_{1} S D_{i}+\beta_{2} E I_{-} S E A_{i} \\
& +\beta_{3} E I_{-} O E A_{i}+\beta_{4} E I_{-} U O E_{i} \\
& +\beta_{5} E I_{-} R O E_{i}+u_{i} \text { with } i=1, \cdots, 404 .
\end{aligned}
$$

Regression model-Equation 2:

$$
\begin{aligned}
& E S P_{i}=\beta_{0}+\beta_{1} S D_{i}+\beta_{2} E I_{-} S E A_{i} \\
& +\beta_{3} E I_{-} O E A_{i}+\beta_{4} E I_{-} U O E_{i} \\
& +\beta_{5} E I_{-} R O E_{i}+u_{i} \text { with } i=1, \cdots, 404 .
\end{aligned}
$$

Regression model-Equation 3:

$$
\begin{aligned}
& E S P_{i}=\beta_{0}+\beta_{1} S D_{i}+\beta_{2} E I_{-} S E A_{i} \\
& +\beta_{3} E I \_O E A_{i}+\beta_{4} E I_{-} U O E_{i} \\
& +\beta_{5} E I_{-} R O E_{i}+\beta_{6} S E_{i}+u_{i} \text { with } i=1, \cdots, 404 .
\end{aligned}
$$

On the first equation the dependent variable SE was regressed on EI and SD (as a control variable). The model was significant $\left(\mathrm{R}^{2}\right.$ Adjusted $\left.=0.477, \mathrm{p}<0.05\right)$. EI_SEA and EI_UOE explained significant variance in $\mathrm{SE}(\beta=0.169, \mathrm{t}=3.923, \mathrm{p}<0.05)$ and $(\beta=0.438, \mathrm{t}=$ $10.314, \mathrm{p}<0.05$ ), checking the first methodological precept. In the second equation ESP was regressed on EI and SD. This model was also significant $\left(\mathrm{R}^{2}\right.$ Adjusted $=$ 0.165, p < 0.05). The EI_SEA and EI_ROE explained significant variance in ESP $(\beta=-0.142, \mathrm{t}=-2.611, \mathrm{p}<$ $0.05)$ and $(\beta=-0.120, t=-2.148, p<0.05)$ checking the second methodological precept.

Finally, the third equation makes the ESP regression on EI sub-dimensions, SD and SE. Although the model was significant $\left(\mathrm{R}^{2}\right.$ Adjusted $\left.=0.163, \mathrm{p}<0.05\right)$, EI_SEA and EI_ROE continue to explain significant variance in ESP $(\beta=-0.139, t=-2.517, p<0.05)$ and $(\beta=-0.120, t$ 
Table 8. T-test for comparing IE mean with POE mean.

\begin{tabular}{ccccccc}
\hline & & & & \multicolumn{2}{c}{$99 \%$ Confidence Interval of the Difference } \\
\hline$t$-test & $\mathrm{t}$ & $\mathrm{df}$ & Sig. (2-tailed) & Mean Difference & Lower & Upper \\
IE-Individual Ethics & 19.006 & 403 & 0.000 & 0.464 & 0.401 & 0.528 \\
\hline
\end{tabular}

Table 9. Regression results testing self-esteem as a mediator of the relationship between EI and ESP.

\begin{tabular}{|c|c|c|c|c|c|c|c|}
\hline & & Equation 1 & & Equation 2 & & Equation 3 & \\
\hline & & $\mathrm{SE}$ & & $\mathrm{ESP}$ & & ESP & \\
\hline Variables & & $\beta$ & $t$ & $\beta$ & $t$ & $\beta$ & $t$ \\
\hline (EI)_SEA-Self-Emotion Appraisal & & $0.169^{* *}$ & 3,923 & $-0.142^{* *}$ & -2.611 & $-0.139^{* *}$ & -2.517 \\
\hline (EI)_OEA-Others Emotion Appraisal & & n.s. & & n.s. & & n.s. & \\
\hline (EI)_ROE_Regulation of Emotion & & n.s. & & $-0.120^{* *}$ & -2.148 & $-0.120^{* *}$ & -2.141 \\
\hline \multirow[t]{7}{*}{ SE-Self-Esteem } & & - & & - & & n.s. & \\
\hline & Total $\mathrm{R}^{2}$ & 0.483 & & 0.176 & & 0.176 & \\
\hline & Total $\mathrm{R}^{2}$ Adjusted & 0.477 & & 0.165 & & 0.163 & \\
\hline & $\Delta \mathrm{R}^{2}$ & - & & - & & 0 & \\
\hline & $\Delta \mathrm{R}^{2}$ Adjusted & - & & - & & -0.002 & \\
\hline & F Test & 74.513 & & 16.978 & & 14.122 & \\
\hline & Sig. & 0.000 & & 0.000 & & 0.000 & \\
\hline
\end{tabular}

Note: $\mathrm{N}=404 ;{ }^{* *} \mathrm{p}<0.05$; All regression coefficients $\beta$ are standardized; n.s.—not significant.

$=-2.141, \mathrm{p}<0.05)$ respectively, not having emerged $\mathrm{a}$ significant influence power by SE that originated the influence reduction of EI. Together, these results do not support the hypothesis 8 nor its partial hypotheses, therefore, and according to Reference [64] and Reference [65] SE can't be classified as mediator since is not significant in the model and did not captured at all or at least decrease the magnitude relationship between EI and ESP.

\section{Conclusion, Discussion and Contributions}

As a characteristic behavioral trait of the studied sector EI shows a positive and significant correlation with IE, POE, SE and SD. The positive correlation between EI and SE is consistent with the research conducted by Reference [54], where a greater EI is associated with high levels of positive thinking and a higher SE. This relationship is stable even in the occurrence of negative nature events. With the ESP, the correlation is negative indicating that in the international business, individuals with higher EI do not perceive the need to resort to unethical conduct in order to achieve success. The higher EI levels of an individual, the highest ethical standards owned and the higher ethical standards perceived in others. On the other hand, the lower EI levels of the individual, with a certain tendency the less ethical will be and more easily will perceive in others unethical behav- iors. Still in relation to POE, it was observed that individuals either with high ethical levels or not consider themselves to be generally more ethical than others. This result is consistent with the literature, since many of those who adopt unethical conduct believe that others who surround them are involved in much worse unethical actions [50,51].

Emotional Intelligence ability of evaluating own emotions reveals to be an ethical behavior predictor. The EISEA (Self-Emotion Appraisal) is correlated with IE, in such a way that individuals who better assess their own emotions present a much smaller involvement in unethical behaviors and much more in ethical than those with low levels of emotional appraisal, since, when increases EI-SEA increases IE.

The SD response emerges as a preponderant factor explaining POE, nullifying the possible predictor effect of EI. Indeed, it is likely that the redundancy effect explained by Reference [65] often verifiable in the social sciences and in organizational psychology be present. This effect refers to the entry of positively correlated predictors among themselves, and as shown in the Table 2, the variables EI and SD exhibit a strong positive correlation ( $r=0.576, p<0.01$ ), leading to like Reference [65] relate, the loss of parsimony in explanation of POE. However, Reference [13] demonstrated that EI has a power of influence in POE. Though, should be noted the achieved result in this study, taking into account the un- 
derlying business environment to the sample integrated into an international business perspective, in which is patent a high behavioral control in order to what is socially well accepted upon the others ethical judgment. It is indeed the SD response that prevails with a high power of influence and predictive $(\beta=0.205, \mathrm{t}=3.408, \mathrm{p}<$ $0.05)$, removing the possible predictive effects of EI in POE. The predictive power of EI as a global construct or its sub-dimensions is totally annihilated by the displayed power of SD. Departing from all living competitive negotiating environment, cultural differences and similar, when individuals evaluate their peers, take into account just what is socially well accepted.

The EI-ROE (Regulation of Emotion) branch, which according to Reference [7] refers to the ability of mood management, monitoring, evaluation and action in emotional control, and the ability to control the emotional reactions of others, explains beyond IE, incremental variance in POE. This result shows that in the exporter organizational spectrum, the ethical level of each individual has implications on how they perceive others. IE levels allies with EI-ROE are significant to explain the perception of others to engage in unethical conduct or not. By regulating emotions, each individual is at a more facilitated level to control others emotions and to perceive their ethical intents. In this sense, the more ethical individuals and those who better regulate emotions, tend to perceive ethical behaviors in others. On the other hand, those who adopt unethical conducts and display lower levels of EI-ROE perceives in others unethical behaviors.

The results suggest specifically that individuals who better evaluate their emotions tend to be more ethical, and the more ethical they are and better regulate emotions, will perceive better ethical levels in others, with the tendency of thinking that their peers are not guided by unethical conduct. On the other hand, individuals who do not evaluate so well their emotions tend to resort to unethical conduct, and the more unethical and less regulate their emotions the higher levels of unethical conduct in others will perceive. Also important, is the fact that the better workers evaluate and regulate their emotions, the lowest levels of unethical conduct they perceive to achieve success.

The SE mediator effect in EI with ESP relationship has not been verified according to the hypothesis 8 results. However, the literature warns to the fact that people with low self-esteem, may consider unethical behaviors as a necessary condition to compete with others [13]. Ethics is linked to success, as well as EI, which also displays a deep connection to organizational success, therefore, more and more personal configuration skills are required, such as emotional competences [53]. These competences are patent in this study and are emphasized in the constructed models. In these companies with high ethics and competitive pressure is visible that the correlation substance of EI with the ESP is so strong that it is not mediated by SE. Emphasis should be made to an effect quite pure and sedimented with negative orientation between EI and ESP.

Social Desirability proved to be predominant in the analysis and shows high predictive and correlating effects with the key variables of the conceptual model. The SD effect has a transversal impact on behavior in environments subject to high competitive, ethical and emotional pressure in business. It was concluded that individuals when emit judgments about their ethical behaviors, ethical behaviors of others, of their EI, SE and their perceptions of the ethics role in success, they do so with a high degree of dependence on cultural definitions and social pressures of what is considered a socially acceptable behavior.

It must be emphasized that this is a very unusual kind of research once and as already stated, according to Reference [13] "one unexplored variable with the potential to impact ethical behavior and decision-making is emotional intelligence” (p. 35), and "to date, no empirical research has examined the Emotional IntelligenceEthical Perceptions link” (p. 36). It is important too, to highlight that this study was conducted in Portugal and in highly competitive companies under high ethical pressures.

Therefore with this background framework, main contributions of this study can be evidenced. Emotional Intelligence showed a positive and significant correlation with Individual Ethics, Perceptions of Others Ethics, Self-Esteem and Social Desirability. The two last results are consistent with the base research of Reference [13], but the first two are different showing that in high competitive companies Emotional Intelligence is much correlated with Individual Ethics and with Perceptions of Others Ethics. Identical to Reference [13] the Ethics and Success Perceptions and Emotional Intelligence correlation is negative, therefore, this research indicate that emotional intelligent individuals do not perceive the need to run in unethical conduct to achieve success in international and highly competitive environment.

As one of the major contributions, this research considers the four sub-dimensions of Emotional IntelligenceSelf-Emotion Appraisal, Others Emotion Appraisal, Use of Emotion and Regulation of Emotion. Therefore, Self-Emotion Appraisal reveals to be an ethical behavior predictor, such that individuals who better assess their own emotions show a considerably smaller involvement in unethical behaviors. In what concerns about Perceptions of Others Ethics and on the contrary of Reference [13] that shows a predictive effect of Emotional Intelligence, this investigation exhibit a nullifying power of Social Desirability on the expected predictor effect of 
Emotional Intelligence, showing that individuals in this kind of environment take into consideration just what is socially well taken.

Reference [13] reveals that Emotional Intelligence added significant incremental variance to Perceptions of Others Ethics. This investigation attests this background finding, although was just one sub-dimension of Emotional Intelligence-Regulation of Emotion, and not the total measure that together with Individual Ethics explains variance in Perceptions of Others Ethics.

In accordance to Reference [13], in this study Emotional Intelligence does not emerged as a moderator between Individual Ethics and Perceptions of Others Ethics. Although while Reference [13] shows that Emotional Intelligence did explain incremental variance in the difference between individual Ethics and Perceptions of Others Ethics, this research show that just the perception of each individual own ethics behavior explain the difference under study.

As can be observed, in this research and consistent with the literature review $[12,13,45,48,49]$ the average of the surveyed individuals reported as being more ethical than their peers.

Another important contribution of this study is the fact that supports that Self-Esteem does not mediate Emotional Intelligence with Ethics and Success Perceptions relationship in spite of the followed study of Reference [13] provided evidence of mediation effect. Once this paper refers to Portugal and to highly competitive companies, it could be verifiable that in the companies that act in highly ethics and competitive pressure environment the relation between Emotional Intelligence with Ethics and Success Perceptions is so pure and so strong that Self-Esteem does not mediate them. Nevertheless, this study state, like Reference [13] and other studies like Reference [54] that high levels of Emotional Intelligence are associated with high levels of Self-Esteem. Still in relation to Ethics and Success Perceptions another relevant contribution is the fact that Social Desirability, Emotional Intelligence in two of the four sub-dimensions - Self-Emotion Appraisal and Regulation of Emotionexplain significant variance. As already assumed this significant relationship proved to be so solid in highly competitive companies that Self-Esteem does not mediate them.

As a final point of contributions, Social Desirability proved to be a very important concept showing high predictive and correlating effects with the key study variables like in the research of Reference [13]. However, and in a quite differently way, this investigation attests the transversal impact of Social Desirability on behavior in highly competitive companies. In this kind of environment it is shown here an elevated dependence on cultural definitions and social pressures of what is consid- ered a socially acceptable behavior.

\section{Limitations and Directions for Future Research}

Currently EI is measured by two methodologies as referred in the literature, the performance-based modelperformance scales, and the mixed models-self-reported scales. It is believed that EI, as a human being performance domain, is more efficiently studied by scales from the performance-based model [27]. For future studies, an alternative to self-report scale WLEIS used in this research passes through the using of another measuring scale of EI not integrated in the mixed models. Using the MSCEIT-Mayer-Salovey-Caruso Emotional Intelligence Test, which as a performance measure is considered the most refined of EI construct analysis as ability [66], may reveal to be interesting from the point of view of EI measurement and its predictive value significance. It should be noted the size of the scale since it will contribute to a substantial lengthening of the questionnaire, as it has 141 items versus the 16 of WLEIS. The used measuring instrument affects the evaluation of a certain reality and the very validity of the studied construct. As the majority of people are not accurate reporters of their own abilities, it should be taken the utmost care when using self-reported measures [21], as was the case in this investigation. Although, this study was based on self-reported measures, we attempted to mitigate the effects of social desirability responses through the statistical control of those responses.

With regard to leadership, and following Reference [67], the relationship between EI and transformational leadership practice is emphasized. It is a little studied relationship, which shows the crucial role of emotions in the emergence of a leader, therefore it is suggested to consider this subject in future studies.

\section{REFERENCES}

[1] D. Goleman, "Inteligência Emocional,” Temas e Debates, Actividades Editoriais, Lda., 1995.

[2] L. Bothwell, “A Arte da Liderança,” Editorial Presença, Lisboa, 1991.

[3] D. Martin and K. Boeck, "QE-O que é a Inteligência Emocional, Cascais,” Pergaminho, Portugal, 1997.

[4] C. C. D. A. B. Rêgo and N. M. F. Rocha, "Avaliando a Educação Emocional: Subsídios para um Repensar da Sala de Aula,” Rio de Janeiro, Vol. 17, No. 62, 2009, pp. 132-152.

[5] J. D. Mayer and P. Salovey, "What Is Emotional Intelligence?” Emotional Development and Emotional Intelligence, Basic Books, New York, 1997, pp. 3-31.

[6] A. Gaudine and L. Thorne, "Emotion and Ethical Decision-Making in Organizations,” Journal of Business Eth- 
ics, Vol. 31, No. 2, 2001, pp. 175-187. http://dx.doi.org/10.1023/A:1010711413444

[7] M. Davies, L. Stankov and R. D. Roberts, "Emotional Intelligence: In Search of an Elusive Construct,” Journal of Personality and Social Psychology, Vol. 75, No. 4, 1998, pp. 989-1015.

[8] T. L. Baker, T. G. Hunt and M. C. Andrews, "Promoting Ethical Behavior and Organizational Citizenship Behaviors: The Influence of Corporate Ethical Values,” Journal of Business Research, Vol. 59, No. 7, 2006, pp. 849-857.

[9] D. S. Carlson, K. M. Kacmar and L. L. Wadsworth, "The Impact of Moral Intensity Dimensions on Ethical Decision Making: Assessing the Relevance of Orientation," Journal of Managerial Issues, Vol. 14, No. 1, 2002, pp. 15-30.

[10] M. L. Fang, "Evaluating Ethical Decision-making of Individual Employees in Organizations-An Integration Framework," The Journal of American Academy of Business, Cambridge, Vol. 8, No. 2, 2006, pp. 105-112.

[11] S. L. Grover, “The Truth, The Whole Truth, and Nothing But The Truth: The Causes and Management of Workplace Lying," Academy of Management Executive, Vol. 19, No. 2, 2005, pp. 148-157.

[12] R. A. Lawson, "Is Classroom Cheating Related to Business Students' Propensity to Cheat in the 'Real World'?” Journal of Business Ethics, Vol. 49, No. 2, 2004, pp. 189-199.

http://dx.doi.org/10.1023/B:BUSI.0000015784.34148.cb

[13] J. Mesmer-Magnus, C. Viswesvaran, S. P. Deshpande and J. Joseph, "Emotional Intelligence, Individual Ethicality, and Perceptions that Unethical Behavior Facilitates Success," Revista de Psicología del Trabajo y de las Organizaciones, Vol. 26, No. 1, 2010, pp. 35-45.

[14] G. Matthews, M. Zeidner and R. D. Roberts, "Introdução," In: Emotional Intelligence: Science and Myth, The Massachusetts Institute of Technology Press, Cambridge, 2002, pp. 1-29.

[15] J. D. Mayer, P. Salovey and D. R. Caruso, "Emotional Intelligence: Theory, Findings, and Implications," Psychological Inquiry, Vol. 15, No. 3, 2004, pp. 197-215.

[16] J. D. Mayer and P. Salovey, "Emotional Intelligence," Imagination, Cognition and Personality, Vol. 9, No. 3, 1990, pp. 185-211.

[17] Z. Ivcevic, M. A. Brackett and J. D. Mayer, "Emotional Intelligence and Emotional Creativity,” Journal of Personality, Vol. 75, No. 2, 2007, pp. 199-235.

[18] R. J. Sternberg, "The Concept of Intelligence and Its Role in Lifelong Learning and Success," American Psychologist, Vol. 52, No. 10, 1997, pp. 1030-1037.

[19] J. D. Mayer, P. Salovey, D. R. Caruso and G. Sitarenios, "Emotional Intelligence as a Satandard Intelligence," Emotion, Vol. 1, No. 3, 2001, pp. 232-242.

[20] N. C. Queroz and A. L. Neri, "Bem-estar Psicológico and Inteligência Emocional entre Homens and Mulheres na Meia-idade and na Velhice," Psicologia: Reflexão and Crítica, Vol. 18, No. 2, 2005, pp. 292-299.

[21] M. A. Brackett and J. D. Mayer, "Convergent, Discriminant, and Incremental Validity of Competing Measures of
Emotional Intelligence," Personality and Social Psychology Bulletin, Vol. 29, No. 10, 2003, pp. 1-12.

[22] D. L. Van Rooy and C. Viswesvaran, "Emotional Intelligence: A Meta-Analytic Investigation of Predictive Validity and Nomological Net," Journal of Vocational Behavior, Vol. 65, No. 1, 2004, pp. 71-95.

http://dx.doi.org/10.1016/S0001-8791(03)00076-9

[23] M. D. Prieto, C. Ferrándiz, M. Ferrando, C. Sánchez and R. Bermejo, "Inteligencia Emocional y Alta Habilidad," Revista Española de Pedagogia, Vol. 240, 2008, pp. 241260.

[24] D. L. Joseph and D. A. Newman, "Emotional Intelligence: An Integrative Meta-analysis and Cascading Model," Journal of Applied Psychology, Vol. 95, No. 1, 2010, pp. 54-78. http://dx.doi.org/10.1037/a0017286

[25] R. C. Solomon, “The Philosophy of Emotions,” In: M. Lewis and J. M. Haviland-Jones, Eds., Handbook of emotions, Guilford Press, New York, 2000, pp. 3-15.

[26] A. Damásio, "O Livro da Consciência-A Construção do Cérebro Consciente,” Círculo de Leitores, 2010.

[27] J. D. Mayer, D. R. Caruso and P. Salovey, "Emotional Intelligence Meets Traditional Standards for an Intelligence,” Intelligence, Vol. 27, No. 4, 2000, pp. 267-298.

[28] C. Cobêro, R. Primi and M. Muniz, "Inteligência Emocional and Desempenho no Trabalho: Um Estudo com MSCEIT, BPR-5 and 16PF," Cadernos de Psicologia and Educação Paidéia, Vol. 16, No. 35, 2006, pp. 337-348.

[29] A. P. P. Noronha, R. Primi, F. A. Freitas and M. A. Dantas, "Análise dos Itens do Mayer-Salovey-Caruso Emotional Intelligence Test: Escalas da Área Estratégica,” Psicologia em Estudo, Vol. 12, No. 2, 2007, pp. 415-422.

[30] A. Martins, N. Ramalho and E. Morin, “A Comprehensive Meta-analysis of the Relationship Between Emotional Intelligence and Health," Personality and Individual Differences, Vol. 49, No. 6, 2010, pp. 554-564.

[31] P. A. G. L. Henriques, “A Gestão do Desenvolvimento dos Recursos Humanos nas Organizações: Uma Abordagem à Gestão Emocional nas Organizações,” Tese de Doutoramento em Gestão apresentada à Universidade Técnica de Lisboa, Lisboa, 2006.

[32] J. Sprea, "Inteligência Emocional: O Diferencial nas Organizações Educacionais Competitivas,” Dissertação de Mestrado em Gestão de Empresas, Instituto Superior de Ciências do Trabalho and da Empresa, Lisboa, 2009.

[33] C. Woyciekoski and C. S. Hutz, "Inteligência Emocional: Teoria, Pesquisa, Medida, Aplicações and Controvérsias,” Psicologia: Reflexão and Crítica, Vol. 22, No. 1, 2008, pp. 1-11.

[34] K. S. Law, C.-S. Wong and L. J. Song, "The Construct and Criterion Validity of Emotional Intelligence and its Potential Utility for Management Studies," Journal of Applied Psychology, Vol. 89, No. 3, 2004, pp. 483-496. http://dx.doi.org/10.1037/0021-9010.89.3.483

[35] J. M. A. Landa, E. López-Zafra, R. M. D. Antoñana and M. Pulido, "Perceived Emotional Intelligence and Life Satisfaction among University Teachers,” Psicothema, Vol. 18, 2006, pp. 152-157.

[36] M. V. Cerezo, M. Ortiz-Tallo and V. Cardenal, "Expresión 
de Emociones y Bienestar En Un Grupo de Mujeres Con Cáncer de Mama: Una Intervención Psicológica,” Revista Latinoamericana de Psicoiogia, Vol. 41, No. 1, 2009, pp. 131-140.

[37] C. S. Wong and K. S. Law, "The Effects of Leader and Follower Emotional Intelligence on Performance and Attitude: An Exploratory Study,” The Leadership Quarterly, Vol. 13, No. 3, 2002, pp. 243-274. http://dx.doi.org/10.1016/S1048-9843(02)00099-1

[38] J. M. Moreira, “A Contas com a Ética Empresarial,” S. João do Estorial, PRINCIPIA, Publicações Universitárias e Científicas, Cascais, 1999.

[39] F. Almeida, "Ética, Valores Humanos e Responsabilidade Social das Empresas,” Princípia Editora, Lda., Cascais 2010.

[40] J. P. Fraedrich, "The Ethical Behavior of Retail Managers," Journal of Business Ethics, Vol. 12, No. 3, 1993 pp. 207218. http://dx.doi.org/10.1007/BF01686448

[41] C. Machado, "Ética: da e na Formação," Revista Portuguesa de Pedagogia, Vol. 39, No. 3, 2005, pp. 129-134.

[42] D. L. Sills, "International Encyclopedia of the Social Sciences,” Vol. 5, The Macmillan Company \& The Free Press, New York, 1972.

[43] D. B. Osorio, "La Conciliación de la Vida Familiar y Laboral: Un Reto Acuciante en la Gestión Empresarial," Estudos Gerenciales, Vol. 26, No. 115, 2010, pp. 65-78.

[44] S. Lysonski and W. Gaidis, "A Cross-Cultural Comparison of the Ethics of Business Students," Journal of Business Ethics, Vol. 10, No. 2, 1991, pp. 141-150. http://dx.doi.org/10.1007/BF00383617

[45] L. F. Pitt and R. Abratt, "Corruption in Business-Are Management Attitudes Right?” Journal of Business Ethics, Vol. 5, No. 1, 1986, pp. 39-44. http://dx.doi.org/10.1007/BF02116141

[46] O. C. Ferrell and J. S. Skinner, "Ethical Behavior and Bureaucratic Structure in Marketing Research Organizations," Journal of Marketing Research, Vol. 25, No. 1, 1988, pp. 103-109.

[47] D. E. Terpstra, E. J. Rozell and R. K. Robinson, "The Influence of Personality and Demographic Variables on Ethical Decisions Related to Insider Trading,” The Journal of Psychology, Vol. 127, No. 4, 1993, pp. 375-389. http://dx.doi.org/10.1080/00223980.1993.9915573

[48] T. Tyson, "Believing that Everyone Else Is Less Ethical: Implications for Work Behavior and Ethics Instruction," Journal of Business Ethics, Vol. 9, No. 9, 1990, pp. 715721. http://dx.doi.org/10.1007/BF00386354

[49] G. M. McDonald and R. A. Zepp, "Ethical Perceptions of Hong Kong Chinese Business Managers," Journal of Business Ethics, Vol. 7, No. 11, 1988, pp. 835-845. http://dx.doi.org/10.1007/BF00383046

[50] R. B. Morgan, "Self- and Co-Worker Perceptions of Ethics and Their Relationships to Leadership and Salary," Academy of Management Journal, Vol. 36, No. 1, 1993, pp. 200-214.

[51] S. J. Vitell and D. L. Davis, "Ethical Beliefs of MIS Professionals: The Frequency and Opportunity for Unethical Behavior,” Journal of Business Ethics, Vol. 9, No. 1,
1990, pp. 63-70. http://dx.doi.org/10.1007/BF00382565

[52] S. P. Deshpande, "The Impact of Ethical Climate Types on Facets of Job Satisfaction: An Empirical Investigation,” Journal of Business Ethics, Vol. 15, No. 6, 1996, pp. 655660. http://dx.doi.org/10.1007/BF00411800

[53] S. Fox and P. E. Spector, "Relations of Emotional Intelligence, Practical Intelligence, General Intelligence, and Trait Affectivity with Interview Outcomes: It's Not All 'G'," Journal of Organizational Behavior, Vol. 21, No. 2, 2000, pp. 203-220.

http://dx.doi.org/10.1002/(SICI)1099-1379(200003)21:2< 203::AID-JOB38>3.0.CO;2-Z

[54] N. S. Schutte, J. M. Malouff, M. Simunek, J. McKenley and S. Hollander, "Characteristic Emotional Intelligence and Emotional Well-Being," Cognition and Emotion, Vol. 16, No. 6, 2002, pp. 769-785.

[55] V. C. Góngora and M. M. Casullo, "Factores Protectores de la Salud Mental: Un Estudio Comparativo Sobre Valores, Autoestima e Inteligencia Emocional en Población Clínica y Población General,” Interdisciplinaria, Vol. 26, No. 2, 2009, pp. 183-205.

[56] F. J. Almeida and F. J. Sobral, "Emoções, Inteligência e Negociação: Um Estudo Empírico Sobre a Percepção dos Gerentes Portugueses,” Revista de Administração Contemporânea (RAC), Vol. 9, No. 4, 2005, pp. 9-30.

[57] J. S. Armstrong and T. S. Overton, "Estimating Nonresponse Bias in Mail Surveys," Journal of Marketing Research, Vol. 14, No. 3, 1977, pp. 396-402. http://dx.doi.org/10.2307/3150783

[58] D. B. Greenberger, M. P. Miceli and D. J. Cohen, “Oppositionists and Group Norms: The Reciprocal Influence of Whistle-Blowers and Co-Workers," Journal of Business Ethics, Vol. 6, No. 7, 1987, pp. 527-542. http://dx.doi.org/10.1007/BF00383744

[59] Â. N. S. Silva, “Auto-Percepções, Auto-Estima, Ansiedade Físico-Social e Imagem Corporal dos Praticantes de Fitness," Universidade de Coimbra, Faculdade de ciências do desporto e educação física, Coimbra, 2007.

[60] D. Marlowe and D. P. Crowne, “A New Scale of Social Desirability Independet of Psychopathology,” Journal of Consulting Psychology, Vol. 24, No. 4, 1960, pp. 349354.

[61] M. H. Pestana and J. N. Gageiro, "Análise de Dados para as Ciências Sociais-A Complementariedade do SPSS,” 5th Edition, Edições Sílabo, Lisboa, 2008.

[62] A. A. Collazo, "Translation of the Marlowe-Crowne Social Desirability Scale into an Equivalent Sapnish Version,” Educational and Psychological Measurement, Vol. 65, No. 5, 2005, pp. 780-806.

[63] J. Maroco, “Análise Estatística-Com Utilização do SPSS,” 1st Edition, Edições Sílabo, Lisboa, 2003.

[64] R. M. Baron and D. A. Kenny, "The Moderator-Mediator Variable Distinction in Social Psychological Research: Conceptual, Strategic, and Statistical Considerations,” Journal of Personality and Social Psychology, Vol. 51, No. 6, 1986, pp. 1173-1182.

[65] G. Abbad and C. V. Torres, "Regressão Múltipla Stepwise e Hierárquica em Psicologia Organizacional: Aplicações, 
Problemas e Soluções,” Estudos de Psicologia, Vol. 7, 2002, pp. 19-29.

[66] R. D. Roberts, C. E. Flores-Mendoza and E. Nascimento, "Inteligência EMocional: Um Constructo Científico?" Cadernos de Psicologia e Educação Paidéia, Vol. 12, No. 23, 2002, pp. 77-92.
[67] E. López-Zafra, R. Garcia-Retamero and J. M. A. Landa, "The Role of Transformational Leadership, Emotional Intelligence, and Group Cohesiveness on Leadership Emergence,” Journal of Leadership Studies, Vol. 2, No. 3, 2008, pp. 37-49. 